IFN Working Paper No. 755, 2008

\title{
Social Interactions and Labor Market Outcomes in Cities
}

Yves Zenou 


\title{
Social Interactions and Labor Market Outcomes in Cities*
}

\author{
Yves Zenou ${ }^{\dagger}$
}

June 12, 2008

\begin{abstract}
We develop a model where information about jobs is essentially obtained through friends and relatives, i.e. strong and weak ties. Workers commute to a business center to work and to interact with other people. We find that housing prices increase with the level of social interactions in the city because information about jobs is transmitted more rapidly and, as a result, individuals are more likely to be employed and to be able to pay higher land rents. We also show that, under some conditions, workers using more their weak ties than strong ties to find a job receive a higher wage. We finally demonstrate that workers living far away from jobs pay lower housing prices but experience higher unemployment rates than those living close to jobs because they mainly rely on their strong ties to obtain information about jobs.
\end{abstract}

Keywords: weak ties, labor market, social networks, land rent.

JEL Classification: A14, J60, R14

*I'm grateful to Joan de Marti for helpful comments. I also thank the Bank of Sweden Tencentary Foundation for financial support.

${ }^{\dagger}$ Stockholm University and Research Institute of Industrial Economics (IFN), Sweden. E-mail: yves.zenou@ne.su.se. 


\section{Introduction}

Social interactions are a key aspect of everyday's life. People interact with each other to exert social activities, exchange information about jobs, etc. These interactions, in particular in the labor market, tend to be localized. For instance, using Census Tract data for Chicago in 1980 and 1990, Topa (2001) finds a significantly positive amount of social interactions across neighboring tracts, especially for areas with a high proportion of less educated workers and/or minorities. Bayer et al. (2005) also document that people who live close to each other, defined as being in the same census block, tend to work together, that is, in the same census block. We do not have however a clear understanding of the mechanisms at work. How do local interactions in the labor market influence wages, employment, and land rents? How localized are these social interactions? What is the impact of commuting costs on social interactions? The aim of this paper is to provide some answers to these questions by developing a model where social interactions, labor and land market aspects are all explicitly taken into account.

In his seminal papers, Granovetter $(1973,1974,1983)$ defines a strong tie as a social relationship between two agents that is repeated over time (for example members of the same family or very close friends) and as weak tie a transitory social encounter between two persons. Granovetter argued that weak ties are superior to strong ties for providing support in getting a job because they involve a secondary ring of acquaintances who have contacts with networks outside ego's network and therefore offer new sources of information on job opportunities. Based on Granovetter's approach, we model social interactions in the labor market by the use of weak and strong ties.

There is a growing interest in theoretical models of peer effects (see e.g. Akerlof, 1997; Glaeser et al., 1996; Ballester et al., 2006), especially in the labor market. However, few models of social networks in the labor market are dynamic. Montgomery (1994) and CalvóArmengol et al. (2007) propose a dynamic model of weak and strong ties but the former focuses on inequality while the latter on the interaction between crime and labor markets. Calvó-Armengol and Jackson (2004) have a more general network analysis (since they can encompass any network structure) but do not model the urban space. To the best of our knowledge, there are nearly no theoretical papers in which social interactions in the labor market are embedded in an urban space. An exception is Selod and Zenou (2006) but there is no explicit analysis of the social network.

To be more precise, we consider a dynamic model of the labor market in which dyad members do not change over time so that two individuals belonging to the same dyad hold a 
strong tie with each other. However, each dyad partner can meet other individuals outside the dyad partnership, referred to as weak ties or random encounters. By definition, weak ties are transitory and only last for one period. The process through which individuals learn about jobs results from a combination of a socialization process that takes place inside the family (in the case of strong ties) and a socialization process outside the family (in the case of weak ties). Bisin and Verdier (2000) refer to the former as vertical socialization and to the latter as oblique socialization. Thus, information about jobs is essentially obtained through friends and relative, i.e. strong and weak ties. Workers commute to a business center to work and to interact with other people. We find that housing prices increase with the level of social interactions in the city because information about jobs is transmitted more rapidly and, as a result, individuals are more likely to be employed and to be able to pay higher land rents. We also show that, under some condition, workers using more their weak ties than strong ties to find a job receive a higher wage.

We then extend this framework by assuming that interactions with weak ties can only take place in the business district since as pointed out by Sigelman et al. (1996) most superficial encounters occur while shopping, going to bars, and the like. Land rents now compensate both for commuting time and social interactions. We find that workers living far away from jobs pay lower housing prices but experience higher unemployment rates than those living close to jobs because they mainly rely on their strong ties to obtain information about jobs.

We finally endogeneize the level of social interactions chosen by individuals. We find that, even though workers want to interact with weak ties because it increases their probability to be employed, workers residing closer to jobs interact more with weak ties than those residing further away from jobs. This is because the marginal gain of interacting with weak ties is higher for workers residing closer to jobs than for those locating further away because of higher pecuniary and time commuting costs.

It has to be emphasized that it is very difficult to combine an explicit network analysis with a finite number of individuals (Vega-Redondo, 2007; Goyal, 2007; Jackson, 2008) with the monocentric city model where a continuum of individuals is considered (Fujita, 1989; Fujita and Thisse, 2002). Our model can be seen a first step towards this direction. One the one hand, the network is extremely simplified since we only consider dyads, i.e., individuals belong to mutually exclusive two-person groups. On the other, because of dyads, we can develop a dynamic model, an essential feature of labor markets. ${ }^{1}$

\footnotetext{
${ }^{1}$ There are some recent papers that combine social interactions and urban spatial structure (Helsley and Strange, 2007; Brueckner and Lagey, 2008). However, in all these papers, the social network is not explicitly
} 


\section{The model}

Consider a population of individuals of size one.

Dyads We assume that individuals belong to mutually exclusive two-person groups, referred to as dyads. We say that two individuals belonging to the same dyad hold a strong tie to each other. We assume that dyad members do not change over time. A strong tie is created once and for ever and can never be broken. Thus, we can think of strong ties as links between members of the same family, or between very close friends.

Individuals can be in either of two different states: employed or unemployed. Dyads, which consist of paired individuals, can thus be in three different states, ${ }^{2}$ which are the following:

(i) both members are employed - we denote the number of such dyads by $d_{2}$;

(ii) one member is employed and the other is unemployed $\left(d_{1}\right)$;

(iii) both members are unemployed $\left(d_{0}\right)$.

Aggregate state By denoting the employment rate and the unemployment rate at time $t$ by $e(t)$ and $u(t)$, where $e(t), u(t) \in[0,1]$, we have:

$$
\left\{\begin{array}{l}
e(t)=2 d_{2}(t)+d_{1}(t) \\
u(t)=2 d_{0}(t)+d_{1}(t)
\end{array}\right.
$$

The population normalization condition can then be written as

$$
e(t)+u(t)=1
$$

or, alternatively,

$$
d_{2}(t)+d_{1}(t)+d_{0}(t)=\frac{1}{2}
$$

modelled. Social interactions are captured by externalities and only average effects are considered.

${ }^{2}$ The inner ordering of dyad members does not matter. 
Social interactions Time is continuous and individuals live for ever. We assume repeated random pairwise meetings over time. Matching can take place between dyad partners or not. At time $t$, each individual can meet a weak tie with probability $\omega(t)$ (thus $1-\omega(t)$ is the probability of meeting his strong-tie partner at time $t){ }^{3}$ Throughout the paper, we assume these probabilities to be constant and exogenous, not to vary over time and thus, they can be written as $\omega$ and $1-\omega$. We will endogeneize $\omega$ in section 6 below. Observe that strong ties and weak ties are assumed to be substitutes, i.e. the more one spends time with weak ties, the less he has time to spend with strong ties.

We refer to matchings inside the dyad partnership as strong ties, and to matchings outside the dyad partnership as weak ties or random encounters. Within each matched pair, information is exchanged, as explained below. Observe that we assume symmetry within each dyad, that is if I meet a strong (or a weak) tie, then my strong (or weak) tie has to meet me. In the language of graph theory, this means that the network of relationships is undirected (see, for example, Jackson, 2008).

Information transmission Each job offer is taken to arrive only to employed workers, who can then direct it to one of their contacts (through either strong or weak ties). This is a convenient modelling assumption, which stresses the importance of on-the-job information. The gist of the analysis would be preserved if this assumption is relaxed. To be more precise, employed workers hear of job vacancies at the exogenous rate $\lambda$ while they lose their job at the exogenous rate $\delta$. All jobs and all workers are identical (unskilled labor) so that all employed workers obtain the same wage. Therefore, employed workers, who hear about a job, pass this information on to their current matched partner, who can be a strong or a weak tie. Thus, information about jobs is essentially obtained through friends and relative.

This information transmission protocol defines a Markov process. The state variable is the relative size of each type of dyad. Transitions depend on labor market turnover and the nature of social interactions as captured by $\omega$. Because of the Markov/Poisson process, the probability of a two-state change is zero (small order) during a small interval of time $t$ and $t+d t$. This means, in particular, that both members of a dyad cannot change their status at the same time. For example, two unemployed workers cannot find a job at the same time, i.e. during $t$ and $t+d t$, the probability assigned to a transition from a $d_{0}-$ dyad to a $d_{2}-$ dyad is zero. Similarly, two employed workers $\left(d_{2}-\right.$ dyad $)$ cannot both become unemployed, i.e. switch to a $d_{0}-$ dyad during $t$ and $t+d t$. This applies to all other dyads mentioned above.

\footnotetext{
${ }^{3}$ If each individual has one unit of time to spend with his friends, then $\omega(t)$ can also be interpreted as the percentage of time spent with weak ties.
} 
Flows of dyads between states It is readily checked that the net flow of dyads from each state between $t$ and $t+d t$ is given by:

$$
\left\{\begin{array}{l}
\dot{d}_{2}(t)=h(e(t)) d_{1}(t)-2 \delta d_{2}(t) \\
\dot{d}_{1}(t)=2 g(e(t)) d_{0}(t)-[\delta+h(e(t))] d_{1}(t)+2 \delta d_{2}(t) \\
\dot{d}_{0}(t)=\delta d_{1}(t)-2 g(e(t)) d_{0}(t)
\end{array}\right.
$$

where $h(e(t)) \equiv[1-\omega+\omega e(t)] \lambda$ and $g(e(t)) \equiv \omega e(t) \lambda$.

Let us explain in details these equation. Take the first one. Then, the variation of dyads composed of two employed workers $\left(\dot{d}_{2}(t)\right)$ is equal to the number of $d_{1}$-dyads in which the unemployed worker has found a job (through either his strong tie with probability $(1-\omega) \lambda$ or his weak tie with probability $\omega e(t) \lambda)$ minus the number of $d_{2}$-dyads in which one of the two employed workers has lost his job. In the second equation, the variation of dyads composed of one employed and one unemployed worker $\left(\dot{d}_{1}(t)\right)$ is equal to the number of $d_{0}$-dyads in which one of the unemployed workers has found a job (only through his weak tie with probability $g(e(t))$ since his strong tie is unemployed and cannot therefore transmit any job information) minus the number of $d_{1}$-dyads in which either the employed worker has lost his job (with probability $\delta$ ) or the unemployed worker has found a job with the help of his strong or weak tie (with probability $h(e(t))$ ) minus the number of $d_{2}$-dyads in which one the two employed has lost his job. Finally, in the last equation, the variation of dyads composed of two unemployed workers $\left(\dot{d}_{0}(t)\right)$ is equal to the number of $d_{1}$-dyads in which the employed worker has lost his job minus the number of $d_{0}$-dyads in which one of the unemployed workers has found a job (only through his strong tie, with probability $g(e(t))$ ) These dynamic equations reflect the flows across dyads. Graphically,

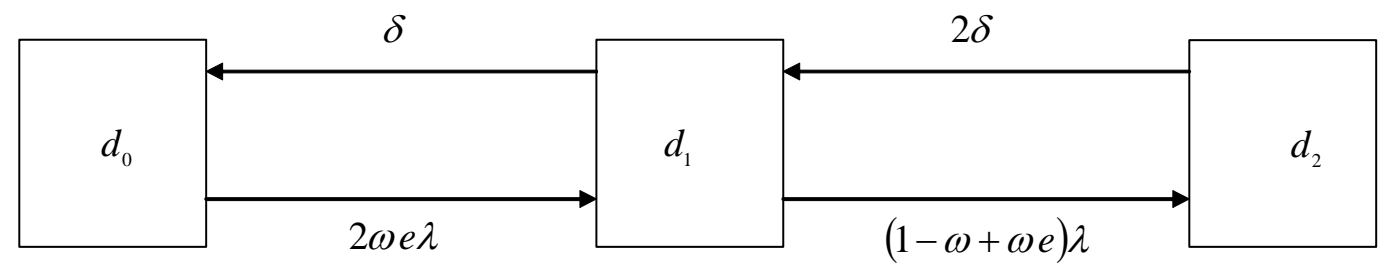

Figure 1: Flows in the labor market

Observe that the assumption stated above that both members of a dyad cannot lose their status at the same time is reflected in the flows described by (4). What is crucial in our analysis is that members of the same dyad (strong ties) always remain together throughout their life. So, for example, if a $d_{2}$-dyad becomes a $d_{0}$-dyad, the members of this dyad are exactly the same; they have just changed their employment status. 
Taking into account (3), the system (4) reduces to a two-dimensional dynamic system in $d_{2}(t)$ and $d_{1}(t)$ given by:

$$
\left\{\begin{array}{l}
\dot{d}_{2}(t)=h(e(t)) d_{1}(t)-2 \delta d_{2}(t) \\
\dot{d}_{1}(t)=2 g(e(t))\left(1 / 2-d_{2}(t)-d_{1}(t)\right)-[\delta+h(e(t))] d_{1}(t)+2 \delta d_{2}(t)
\end{array}\right.
$$

where, using (1):

$$
e(t)=2 d_{2}(t)+d_{1}(t)
$$

\section{Steady-state equilibrium analysis}

A steady-state equilibrium requires solving simultaneously two problems:

(i) (steady state) labor flows (referred to as a labor market equilibrium);

(ii) a location and rental price outcome (referred to as an urban land use equilibrium)

For convenience, we expose first the steady-state labor market equilibrium and then the urban land use equilibrium.

\subsection{Labor market equilibrium}

In a steady-state $\left(d_{2}^{*}, d_{1}^{*}, d_{0}^{*}\right)$, each of the net flows in (4) is equal to zero. Setting these net flows equal to zero leads to the following relationships:

$$
\begin{gathered}
d_{2}^{*}=\frac{\left(1-\omega+\omega e^{*}\right) \lambda}{2 \delta} d_{1}^{*} \\
d_{1}^{*}=\frac{2 \omega e^{*} \lambda}{\delta} d_{0}^{*}
\end{gathered}
$$

where

$$
\begin{gathered}
d_{0}^{*}=\frac{1}{2}-d_{2}^{*}-d_{1}^{*} \\
e^{*}=2 d_{2}^{*}+d_{1}^{*} \\
u^{*}=1-e^{*}
\end{gathered}
$$

Definition 1 A steady-state labor market equilibrium is a four-tuple $\left(d_{2}^{*}, d_{1}^{*}, d_{0}^{*}, e^{*}, u^{*}\right)$ such that equations (5), (6), (7), (8) and (9) are satisfied. 
Define $Z=(1-\omega) / \omega, B=\delta /(\lambda \omega)$. We have the following result.

\section{Proposition 1}

(i) There always exists a steady-state equilibrium $\mathcal{U}$ where all individuals are unemployed and only $d_{0}-$ dyads exist, that is $d_{2}^{*}=d_{1}^{*}=e^{*}=0, d_{0}^{*}=1 / 2$ and $u^{*}=1$.

(ii) If

$$
\delta<\lambda[\omega+\sqrt{\omega(4-3 \omega)}] / 2
$$

there exists a steady-state equilibrium $\mathcal{I}$ where $0<e^{*}<1$ is defined by

$$
e^{*}=\frac{B^{2}}{2 d_{0}^{*}}-B-Z>0
$$

$0<u^{*}<1$ by (9), and $0<d_{0}^{*}<1 / 2$ is the unique (feasible) solution of the following equation:

$$
-\frac{Z}{B} d_{0}^{* 2}-\frac{(1+Z)}{2} d_{0}^{*}+\left(\frac{B}{2}\right)^{2}=0
$$

Also, the other dyads are given by:

$$
\begin{gathered}
d_{1}^{*}=\frac{2 e^{*}}{B} d_{0}^{*} \\
d_{2}^{*}=\frac{\left(Z+e^{*}\right) e^{*}}{B^{2}} d_{0}^{*}
\end{gathered}
$$

If condition (10) holds, then an interior equilibrium always exists. Indeed, the jobdestruction rate $\delta$ has to be not too large and the job-contact rate $\lambda$ high enough for the interior equilibrium. Otherwise, all workers will be unemployed and the steady-state equilibrium $\mathcal{U}$ will prevail. The latter is obviously uninteresting and, from now on, we only focus on the labor market equilibrium $\mathcal{I}$.

\subsection{Urban land-use equilibrium}

Consider a continuum of equally productive workers uniformly distributed along a linear and closed city. All land is owned by absentee landlords and all firms are exogenously located in the Business District (BD hereafter). The BD is a unique employment center located at one end of the linear city. In a centralized city, it corresponds to the Central Business District, 
whereas in a completely decentralized city, it represents suburban employment. Workers are risk neutral, optimally decide their place of residence between the BD and the other end of the city, and all consume the same amount of land (normalized to 1 for simplicity). Without loss of generality, the density of residential land parcels is taken to be unity, so that there are exactly $x$ units of housing within a distance $x$ from the BD. As stated above, the total population is normalized to 1 .

Each individual is identified with one unit of labor. Each employed worker goes to the BD to work and incurs a fixed monetary commuting cost $\tau$ per unit of distance. When living at a distance $x$ from the $\mathrm{BD}$, he also pays a land rent $R(x)$, consumes 1 unit of land and $z_{L}$ unities of the non-spatial composite good (which is taken as the numeraire so that its price is normalized to 1) and earns a wage $y$. The wage is assumed to be exogenous. ${ }^{4}$ For example, one could think of a minimum wage that is exogenously fixed by the government. The instantaneous (indirect) utility of an employed worker located at a distance $x$ from the $\mathrm{BD}$ is equal to:

$$
V_{1}(x)=y-\tau x-R(x)
$$

Concerning the unemployed workers, they commute less often to the BD since they essentially go there for interacting with other people (see section 6 for an explicit modelling of this issue). So, we assume that the unemployed workers incur a commuting $\operatorname{cost} s \tau$ per unit of distance, where $0<s \leq 1$. For example $s=1$ would mean that the unemployed workers go everyday to the $\mathrm{BD}$ (as often as the employed workers) whereas, if $s=1 / 2$, then the unemployed make only half as many BD-trips as the employed workers. The instantaneous (indirect) utility of an unemployed worker residing at a distance $x$ from the BD is therefore equal to:

$$
V_{0}(x)=b-s \tau x-R(x)
$$

where $b<y$ is the unemployment benefit. We assume that $b$ is exogenously financed by taxpayers who reside elsewhere (for example absentee landlords).

We are now able to calculate the expected utility of each worker. To do that, as in Zenou (2006a), we assume perfect capital markets with a zero interest rate. ${ }^{5}$ With perfect

\footnotetext{
${ }^{4}$ This wage will be endogeneized in section 5 below.

${ }^{5}$ When there is a zero interest rate, workers have no intrinsic preference for the present so that they only care about the fraction of time they spend employed and unemployed. Therefore, the expected utilities are not state dependent.
} 
capital markets, workers are able to smooth their disposable income over time so that at any moment in time, the disposable income of a worker is equal to his average net income over the job cycle. Therefore, the expected utility of a worker residing in $x$ is given by:

$$
E V(x)=e^{*}(\omega) V_{1}(x)+\left[1-e^{*}(\omega)\right] V_{0}(x)
$$

Indeed, over his lifetime, in steady-state, each employed worker spends $e^{*}(\omega)=d_{1}^{*}+2 d_{2}^{*}$ of his time employed and $1-e^{*}(\omega)=2 d_{0}^{*}+d_{1}^{*}$ of his time unemployed. Since there is zero interest rate, people only care about the time they spend in each dyad. Using (15) and (16), this expected utility can be written as:

$$
E V(x)=e^{*}(\omega)(y-\tau x)+\left[1-e^{*}(\omega)\right](b-s \tau x)-R(x)
$$

where $e^{*}(\omega)$ is given by (11). Observe that, in order to write this expected utility, we have implicitly assumed that, because workers are able to smooth their income over time, a worker's residential location remains fixed as he enters and leaves unemployment. This is indeed more realistic than assuming that changes in employment status involve changes in residential location. So, here, relocation costs are so high that workers always stay at the same location and are not affected by the change of their status.

Let us now solve the urban land use equilibrium. The timing is as follows. Assume that there is an initial situation when workers pick locations without knowing their initial employment status. They will not change location afterwards. Then, given zero discounting and income smoothing, people bid for rents given that they anticipate the time they will spend in each employment state. Thus, the whole structure of the analysis is: $(i)$ initial period location determination; ( $i i$ ) ensuing labor market shocks resulting in unemployment, wage, etc... In equilibrium, because of the competition in the land/housing market, all ex ante identical workers will obtain the same expected utility $\overline{E V}$. It should be clear that the presence of high-relocation costs means that there is no bidding after initial location decisions.

We now need to calculate the bid rent of workers $\Psi(x, \overline{E V})$, which is defined as the maximum land rent that a worker is willing to pay at a given location $x$ so as to reach a given level of utility $\overline{E V}$. By solving $(17)$ in $R(x)=\Psi(x, \overline{E V})$ for the utility level $\overline{E V}$, we easily obtain the following linear bid rent function:

$$
\Psi(x, \overline{E V})=e^{*}(\omega)(y-\tau x)+\left[1-e^{*}(\omega)\right](b-s \tau x)-\overline{E V}
$$

with

$$
\frac{\partial \Psi(x, \overline{E V})}{\partial x}=-\left[e^{*}(\omega)+\left[1-e^{*}(\omega)\right] s\right] \tau<0
$$


Indeed, in this model, bid rents compensate workers for their expected commuting costs. Those who live close to jobs pay higher land rents because they have lower pecuniary costs whether they are employed or not while those who live far away from jobs have the reverse. By normalizing the agricultural land to zero and by noticing that the size of the city is equal to 1 , we have the following definition:

Definition 2 An urban land-use equilibrium is a couple $\left(\overline{E V}^{*}, R^{*}(x)\right)$ such that:

$$
\begin{gathered}
\Psi\left(1, \overline{E V}^{*}\right)=0 \\
R^{*}(x)=\max \left\{\Psi\left(x, \overline{E V}^{*}\right), 0\right\}
\end{gathered}
$$

The first equation guarantees that the land rent is continuous everywhere in the city while the second equation is such that absentee landlords allocate land to the highest bidder. Solving (18) and (19) gives:

Proposition 2 At the urban land use equilibrium, we obtain:

$$
\overline{E V}^{*}=e^{*}(\omega)(y-\tau)+\left[1-e^{*}(\omega)\right](b-s \tau)
$$

and for $0 \leq x \leq 1$,

$$
R^{*}(x)=\left\{e^{*}(\omega)+\left[1-e^{*}(\omega)\right] s\right\} \tau(1-x)
$$

We can define the general equilibrium where both the steady-state interior labor and urban land-use equilibria are solved for simultaneously. Ignoring the equilibrium $\mathcal{U}$, we have the following result:

Proposition 3 If (10) holds, then there exists an interior steady-state equilibrium where the endogenous variables $\left(u^{*}, e^{*}, d_{0}^{*}, d_{1}^{*}, d_{2}^{*}, \overline{E V}^{*}, R^{*}(x)\right)$ are respectively determined by (9), (11), (12), (13), (14), (20) and (21).

\section{Social interactions}

The most interesting results of this model is the impact of social interactions (captured by $\omega)$ on the different endogenous variables. We have a first important result. 


\section{Proposition 4 Assume}

$$
\frac{\delta}{\lambda}<\sqrt{\frac{\omega}{6}}
$$

and consider steady-state equilibrium $\mathcal{I}$. Then, increasing the percentage of weak ties $\omega$ decreases both the number of $d_{0}-d y a d s$ and the unemployment rate $u^{*}$ in the economy, i.e.

$$
\frac{\partial d_{0}^{*}}{\partial \omega}<0 \quad, \quad \frac{\partial u^{*}}{\partial \omega}<0
$$

The effects of $\omega$ on $d_{1}^{*}$ and on $d_{2}^{*}$ are however ambiguous.

Proof. See the Appendix.

Here, individuals belong to mutually exclusive groups, the dyads, and weak tie interactions spread information across dyads. The parameter $\omega$ measures the proportion of social interaction that occurs outside the dyad, the inter-dyad interactions. When $\omega$ is high, the social cohesion between employed and unemployed workers is high and thus they are in close contact with each other. In this context, increasing $\omega$ induces more transitions from unemployment to employment and thus $u^{*}$, the unemployment rate in the economy decreases. This is not always true since it depends on the value of $\lambda$ (job contact rate) relative to the value of $\delta$ (the job destruction rate). A sufficient condition for $\frac{\partial u^{*}}{\partial \omega}<0$ is (22), which guarantees that (10) holds (see the Appendix). Even though $u^{*}$ decreases, the effect of $\omega$ on $d_{2}^{*}$ and $d_{1}^{*}$ is ambiguous. Indeed, from Figure 1 , individuals leave dyad $d_{1}$ and enters dyad $d_{2}$ at rate $h(e) \equiv(1-\omega+\omega e) \lambda$. Now since

$$
\frac{\partial[(1-\omega+\omega e) \lambda]}{\partial \omega}=\left(-1+e+\omega \frac{\partial e}{\partial \omega}\right) \lambda
$$

is ambiguous (since $-1+e<0$ ), the effects mentioned above are also ambiguous. Now consider the effect of $\omega$ on $d_{0}^{*}$. This is clearly negative. Indeed, from Figure 1, one can see that individuals leave dyad $d_{0}$ at rate $2 \omega e \lambda$. Since

$$
\frac{\partial(2 \omega e \lambda)}{\partial \omega}=2 \lambda\left(e+\omega \frac{\partial e}{\partial \omega}\right)>0
$$

then, when $\omega$ increases, there are fewer $d_{0}$-dyads.

Proposition 5 Assume (22) and consider steady-state equilibrium $\mathcal{I}$. Then, increasing the percentage of weak ties $\omega$ increases both the price of land (and housing) everywhere in the city and the utility level of all workers, i.e.

$$
\frac{\partial R^{*}(x)}{\partial \omega}>0, \forall x \in[0,1]
$$




$$
\frac{\partial \overline{E V}^{*}}{\partial \omega}>0
$$

Indeed, when the strength of weak ties $\omega$ increases, people find jobs more easily and thus spend more time employed during their lifetime. As a result, there are able to bid more for land and thus the competition in the land market becomes fiercer. Consequently, the price of land and housing increases at each location in the city. Because the positive impact of $\omega$ on employment is large enough to outweight the negative effect of the land rent, the expected utility increases with an increase in $\omega$. The effect of weak ties on the land rent is an interesting and new result. It is though simple and intuitive since it says that if there are more social interactions in an area, then information about jobs is transmitted more rapidly and, as a result, more people would be employed and land rents would be higher. There is a recent paper by $\mathrm{Fu}$ (2005) who tests in some sense this result. Fu (2005) uses the 1990 Massachusetts census data and estimates hedonic housing model with social amenities. He found that an increase in the percentage of new residents has significant positive effects on property values. He concludes that this is "probably due to the strength of weak ties". Of course, it could also be consistent with other aspects such as, for example, gentrification. The results of a direct empirical test of the impact of social interactions on land rents will be very interesting and will help us to verify if the prediction of our model is correct.

\section{Endogenous wages}

In this section, we endogenously determine the wage $y$. For that, we use an efficiency wage model (Shapiro and Stiglitz, 1984) where firms set wages to deter shirking. There are only two possible effort levels: either the worker shirks, exerts zero effort, $a=0$, and contributes to zero production, or he/she does not shirk, provides full effort, $a>0$, and contributes to 1 unit of production.

As before, there is a stochastic process in employment status changes. However, firms cannot perfectly monitor workers, so there is a rate at which shirking is detected, denoted by $m$ (i.e. monitoring rate). If a worker is caught shirking, he is automatically fired. As a result, for non-shirkers, the stochastic process is as before and described by Figure 1. However, for shirkers, it is as in Figure 1 with one difference: $\delta$ is replaced by $\delta+m$, since shirkers can lose their jobs either because there is a technological shock that leads to the destruction of the job or because the worker has been caught shirking and fired. The rest of the stochastic process is the exactly the same as in the previous section. In particular, the way workers find a job and transmit information within and outside the dyad is the same. 
As a result, the employment rate for non-shirkers, $e^{*}(\omega)=e^{N S}(\omega)$ is still given by (11), while the employment rate for shirkers $e^{S}(\omega)$ is defined by (11), where $\delta$ is replaced by $\delta+m$.

We can now write the expected utilities. For a non shirker located at a distance $x$ from the $\mathrm{BD}$, his expected utility is equal to:

$$
E V^{N S}(x)=e^{*}(\omega)(y-a-\tau x)+\left[1-e^{*}(\omega)\right](b-s \tau x)-R(x)
$$

whereas, for a shirker residing at a distance $x$ from the $\mathrm{BD}$, it is given by:

$$
E V^{S}(x)=e^{S}(\omega)(y-\tau x)+\left[1-e^{S}(\omega)\right](b-s \tau x)-R(x)
$$

The trade off between shirking and non shirking is clear: shirkers do not provide effort $a$ but spend more time unemployed. Let us calculate the efficiency wage. Firms know that workers have a zero discount rate, so, at each $x$, they solve $E V^{N S}(x)=E V^{S}(x)$. By using (23) and (24), we easily obtain the following efficiency wage:

$$
y^{e f f}=b+a \frac{e^{*}(\omega)}{\left[e^{*}(\omega)-e^{S}(\omega)\right]}+(1-s) \tau x
$$

Equation (25) is also referred to as the non-shirking condition. The information available to firms about workers' residence matters in the process of wage formation. If firms perfectly observe the residential location of all workers, then they will set the wage (25) at each location $x$. In firms do not perfectly observe the residential location of all workers in the city, then, to prevent shirking, they will set the highest possible wage, i.e. the one for the worker located at the city fringe $x=1$. In that case, the efficiency wage for all workers will be given by:

$$
y^{e f f}=b+a \frac{e^{*}(\omega)}{\left[e^{*}(\omega)-e^{S}(\omega)\right]}+(1-s) \tau
$$

This is the case we consider now ${ }^{6}$ i.e. firms do not have perfect information on workers' residence. ${ }^{7}$ This efficiency wage has the standard properties of non-spatial models (Shapiro and Stiglitz, 1984). Indeed, when $b, a$, or $\delta$ increases, or $m$ decreases (these are the nonspatial effects), the efficiency wage has to increase in order to prevent shirking. The spatial aspect of the wage is determined by the positive relationship between (efficiency) wages and commuting costs. Indeed, when someone shirks, only the gain in commuting costs is (positively) affected by $x$, the distance to jobs. So, the further away from the BD a worker

\footnotetext{
${ }^{6}$ The case of perfect infomation is straightforward to analyze.

${ }^{7}$ It is also the more realistic case since workers can misreport their residential address.
} 
resides, the higher the benefit of shirking in terms of commuting costs. As a result, if firms want to induce workers not to shirk at each $x$, they have to increase the wage for workers living further away from jobs in order to exactly compensate the additional gain from shirking, that is $(1-s) \tau x$. In the case of imperfect information, the spatial compensation is for the worker located at $x=1$ and it is thus equal to $(1-s) \tau$.

What is new in the present model is the impact of social interactions $\omega$ on wages. The term $\frac{e^{*}(\omega)}{e^{*}(\omega)-e^{S}(\omega)}$ captures the incentive aspect of the efficiency wage, ${ }^{8}$ i.e. the amount necessary to prevent shirking. As in Shapiro and Stiglitz (1984), it is a function of employment (or unemployment) since unemployment acts as a worker discipline device. Denote $\Delta e \equiv \frac{e^{*}(\omega)-e^{S}(\omega)}{e^{*}(\omega)}>0$, i.e. the difference in employment rates between shirking and nonshirking behaviors, then

$$
y^{e f f}=b+\frac{a}{\Delta e}+(1-s) \tau
$$

Indeed, the higher the difference in employment rate between shirking and non-shirking behaviors, the less workers are induced to shirk, and the lower the efficiency wage needed to reduce shirking. Define

$$
\eta_{\omega}^{N S} \equiv \frac{\partial e^{*}(\omega)}{\partial \omega} \frac{\omega}{e(\omega)}
$$

as the elasticity of non-shirking employment with respect to weak ties and

$$
\eta_{\omega}^{S} \equiv \frac{\partial e^{S}(\omega)}{\partial \omega} \frac{\omega}{e^{S}(\omega)}
$$

as the elasticity of shirking employment with respect to weak ties. We have the following result:

Proposition 6 Assume (22) and consider steady-state equilibrium $\mathcal{I}$. Then

$$
\frac{\partial y^{e f f}}{\partial \omega} \gtreqless 0 \Leftrightarrow \eta_{\omega}^{N S} \lesseqgtr \eta_{\omega}^{S}
$$

When interactions with weak ties $\omega$ increase, under condition (22), whether they shirk or not, workers are on average more employed over their lifecycle. However, if the responsiveness of employment to $\omega$ is higher for shirkers than non-shirkers, then firms need to increase the efficiency wage to deter shirking. This is an interesting result because it links social interactions and wages. In particular, it says that, if workers use more their weak ties than strong ties to find a job, then they will receive higher wages if the elasticity of shirking employment with respect to weak ties is higher than that of non shirking.

\footnotetext{
${ }^{8}$ Observe that, by definition, $e^{*}(\omega)>e^{S}(\omega)$.
} 
As in the standard efficiency wage model, we can close the model by modelling the behavior of firms. Consider $M$ identical firms $(j=1, \ldots, M)$ in the economy. All firms produce the same composite good and sell it at a fixed market price $p$ (this good is taken as the numeraire and its price $p$ is set to 1 ). Firms only care of workers' productivity on the job and their main objective is to prevent shirking because it is very costly (workers produce nothing if they shirk). ${ }^{9}$ On the contrary, each worker, whatever his location, contributes to one unit of production if he does not shirk (which will always be true in equilibrium). The production function of each firm $j$ is: $F\left(l_{j}\right)$ and it is assumed that $F(\cdot)$ is twice differentiable, with $F(0)=0, F^{\prime}(\cdot)>0$ and $F^{\prime \prime}(\cdot) \leq 0$, and it satisfies the Inada conditions, i.e. $F^{\prime}(0)=+\infty$ and $F^{\prime}(+\infty)=0$.

Since all firms are identical, let us focus on a symmetric (steady-state) equilibrium in which each firm employs the same number of workers. This means that each firm $j$ hires $L_{j}=L=e^{*}(\omega) / M$ workers, where $e^{*}(\omega)$ is given by (11). As a result, each firm adjusts employment until the marginal product of an additional worker equals the efficiency wage (26). We obtain:

$$
b+a \frac{L^{*} M}{L^{*} M-e^{S}(\omega)}+(1-s) \tau=F^{\prime}\left(L^{*}\right)
$$

Because of the assumptions made on the production function, it is easy to show that there exists a unique solution in $L^{*}$. Because $L^{*}=e^{*}(\omega) / M$, and $e^{*}(\omega)$ is given by (11), $M$ will adjust so that $L^{*}=e^{*}(\omega) / M$ will be always true in equilibrium.

\section{Social interactions and distance to jobs}

We would like now to endogeneize $\omega$. We first endogeneize it by imposing a relationship between $\omega$ and $x$. We will then derive this relationship endogenously by letting workers choosing optimally $\omega$. In this section, for simplicity, we will consider the wage $y$ as exogenous. Making it endogenous as in the previous section will not change any of our main results but will make the analysis more cumbersome.

\subsection{Exogenous relationship between weak ties and distance to jobs}

It should be clear that the relationships with strong ties are in general not costly while relationships with weak ties, which are random encounters, involve some costs. Here, we

\footnotetext{
${ }^{9}$ Because $\omega$ has an impact on the efficiency wage, one could argue that firms could hire people depending on how they find a job. We assume that firms do not know if workers have found a job through their weak or strong ties. As a result, when deciding wage and employment, each firm takes $\omega$ as given.
} 
mainly focus on spatial costs and assume that weak ties only meet in the business district. Formally, it is assumed that $\omega$ is a decreasing function of $x$, i.e. $\omega(x)$ with $\omega^{\prime}(x)<0 .{ }^{10,11}$ As expressed by Glaeser (2000), "social influences decay rapidly with distance". Indeed, interacting with strong ties (family members or best friends) has no real cost: either they live in the same location or one just needs to make a phone call to have a contact with a strong tie. So basically, strong ties provide information at no cost, especially no spatial costs. This is well documented empirically. For example, Topa (2001) and, more recently, Bayer et al (2005) found evidence of significant social interactions operating at the block level. ${ }^{12}$ In our model, these are interactions between strong ties since they are repeated over time.

On the contrary, having contact with weak ties, defined as relationships with random encounters that are not repeated over time, involves costs (of any kind). Here we mainly focus on spatial costs (we could easily incorporate other costs) and we assume that weak ties only meet in the business district, which involves (both pecuniary and time) costs of commuting to the BD. ${ }^{13}$ For example, individuals go to a bar or play bowling or go shopping and then may meet other people. In our dynamic model, at each period, people meet different weak ties. Henning and Lieberg (1996) investigate the structure of networks and the content of ties in selected neighborhoods in Linköping, Sweden. Strong ties were those of importance to the respondent and which were characterized by regular contact. Weak ties consisted of nodding acquaintances and conversational contacts. Henning and Lieberg found that neighborhood where people live was relatively unimportant in weak ties relationships for both white collar and blue-collar residents - three quarters of contacts were outside the local area.

Thus, compared to the previous section, we assume that individuals meet their strong ties locally without needing to commute while they need to go to the BD to meet weak ties.

In that case, Proposition 1 is exactly as before with one difference, which is that all endogenous variables (i.e. $u^{*}, e^{*}, d_{0}^{*}, d_{1}^{*}$ and $d_{2}^{*}$ ) are now a function of $x$ and not of $\omega$ (and of course a function of all the other exogenous variables). In particular, this means that, if

\footnotetext{
${ }^{10}$ We can further assume that $\omega(1)=0$ and $\omega(0)=1$, which implies that, at the $\mathrm{BD}(x=0)$, individuals interact only with weak ties while at the city fringe $(x=1)$, they interact only with strong ties. This is not necessary for our main results.

${ }^{11}$ In section 6.2 below, $\omega$ will be endogeneously chosen by individuals and we will show under which condition $\omega$ is a negative function of $x$.

${ }^{12}$ See also Kan (2007) who shows social capital to be very local.

${ }^{13}$ Using a different model, Helsey and Strange (2007) model social interactions in a similar way since all social interactions occur at a single location (the "center") and are defined as the number of visits to the center.
} 
condition (22) holds, then:

$$
\begin{aligned}
& \frac{\partial d_{0}^{*}}{\partial x}=\frac{\partial d_{0}^{*}}{\partial \omega} \frac{\partial \omega}{\partial x}>0 \\
& \frac{\partial u^{*}}{\partial x}=\frac{\partial u^{*}}{\partial \omega} \frac{\partial \omega}{\partial x}>0
\end{aligned}
$$

Indeed, for individuals living far away from jobs, it is more costly to travel to the BD and thus are less likely to meet weak ties who can provide information about jobs. So, for example, if someone is unemployed and belongs to a $d_{0}-$ dyad, then the only persons who can provide information about jobs are weak ties. But if this person lives far away from the BD, he will go less often there and thus will have little information about jobs.

In that case, this expected utility can be written as:

$$
E V(x)=e^{*}(x)(y-\tau x)+\left[1-e^{*}(x)\right](b-s \tau x)-R(x)
$$

and thus the bid rent function is given by:

$$
\Psi(x, \overline{E V})=e^{*}(x)(y-\tau x)+\left[1-e^{*}(x)\right](b-s \tau x)-\overline{E V}
$$

This bid rent is not anymore linear. Indeed, we have:

$$
\frac{\partial \Psi(x, \overline{E V})}{\partial x}=\frac{\partial e^{*}(x)}{\partial x}[y-b-(1-s) \tau x]-(1-s) \tau e^{*}(x)-s \tau
$$

which is strictly negative since $0<e^{*}(x)<1$ and $e^{*}(x)=1-u^{*}(x), \forall x \in[0,1]$. The role of the land rent is now to compensate remote locations for both higher commuting costs and higher unemployment rate.

Adopting the same definition of equilibrium as in Definition 2, we obtain:

Proposition 7 At the urban land use equilibrium where social interactions $\omega$ is a function of distance to jobs $x$, we obtain:

$$
E V^{*}=e^{*}(1)(y-\tau)+\left[1-e^{*}(1)\right](b-s \tau)
$$

and for $0 \leq x \leq 1$,

$$
R^{*}(x)=e^{*}(x)[y-b-(1-s) \tau x]-e^{*}(1)[y-b-(1-s) \tau]+s \tau(1-x)
$$


To illustrate the model, we perform some numerical simulations.

The period is the month. We assume a wage of $w=4$ and the unemployment benefit is set to $b=1.25$, so that the replacement rate is $b / w=0.31$. The job destruction rate is equal to $\delta=0.01$, that is, workers keep on average their job 100 months or a little bit more than 8 years. The job acquisition rate is equal to $\lambda=0.1$. In the city, we set $\tau=0.5$ and $s=0.5$ (the unemployed make half as many BD-trips as the employed workers). Concerning social interactions, we assume the following function: ${ }^{14}$

$$
\omega(x)=\frac{1}{1+10 x}
$$

which is decreasing and convex in $x$. Figures $2 \mathrm{a}-2 \mathrm{~d}$ display the results of the simulations. Let us interpret them. In steady-state, all workers in the city have the same utility level given by (33) whatever their location $x$. However, they do not experience the same unemployment rate and do not pay the same land rent. This depends on their location $x$ in the city. These figures show that people living closer to jobs experience a lower unemployment rate than those living further away from jobs (Figure 2a) because they spend less time in a $d_{0}-$ dyad (Figure 2b) and more time in a $d_{1}-$ dyad (Figure 2c). The intuition of this result is straightforward. Individuals living closer to jobs meet more often weak ties and thus obtain more information about jobs. As a result, they do not spend much time in a $d_{0}$-dyad since the only way to leave this dyad is to obtain a job through a weak tie. There are important variations of unemployment rates following variations of the location $x$. For $x=1$ (i.e. individuals live the farthest away from the jobs), then the unemployment rate $u^{*}$ is equal to 17.74 percent while for $\omega$ close to zero (i.e. individuals live the closest to jobs), then $u^{*}=10$ percent.

\footnotetext{
${ }^{14}$ Observe that because $0 \leq x \leq 1$, this function imposes that $0.09 \leq \omega \leq 1$. This is just for simplicity. We could have taken for example$$
\omega(x)=\frac{1}{1+a x}
$$

In that case, when $a$ is sufficiently large, $\omega(x)$ is close to zero when $x=1$.
} 


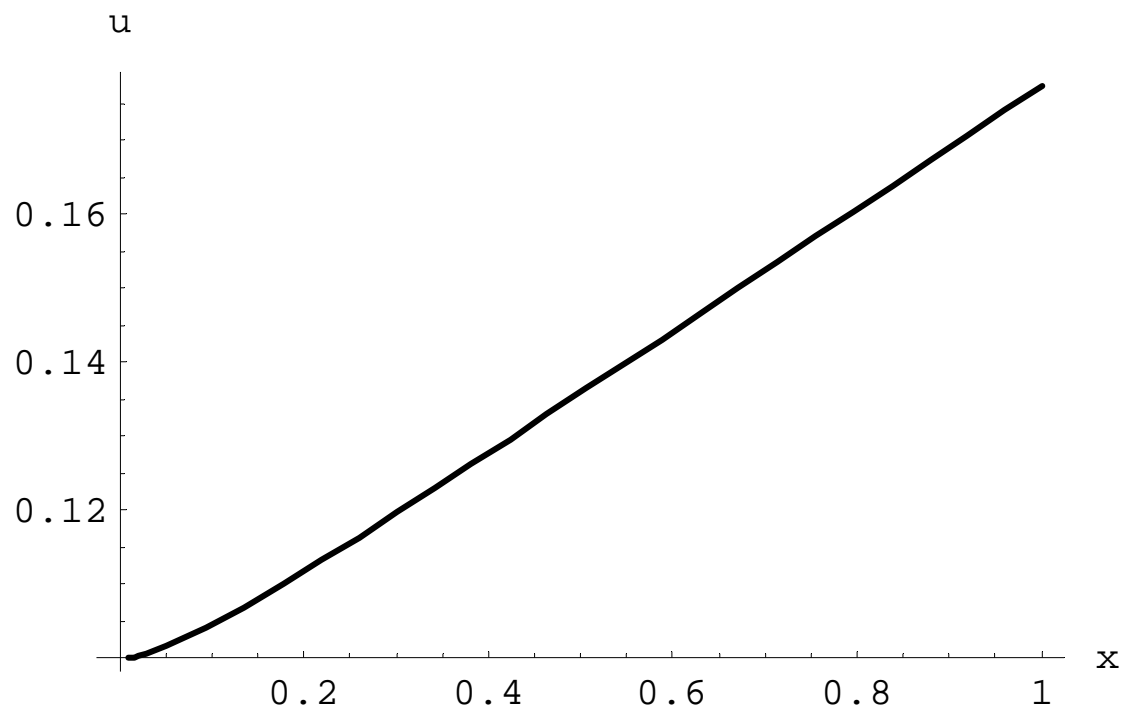

Figure 2a: Impact of distance to jobs on unemployment

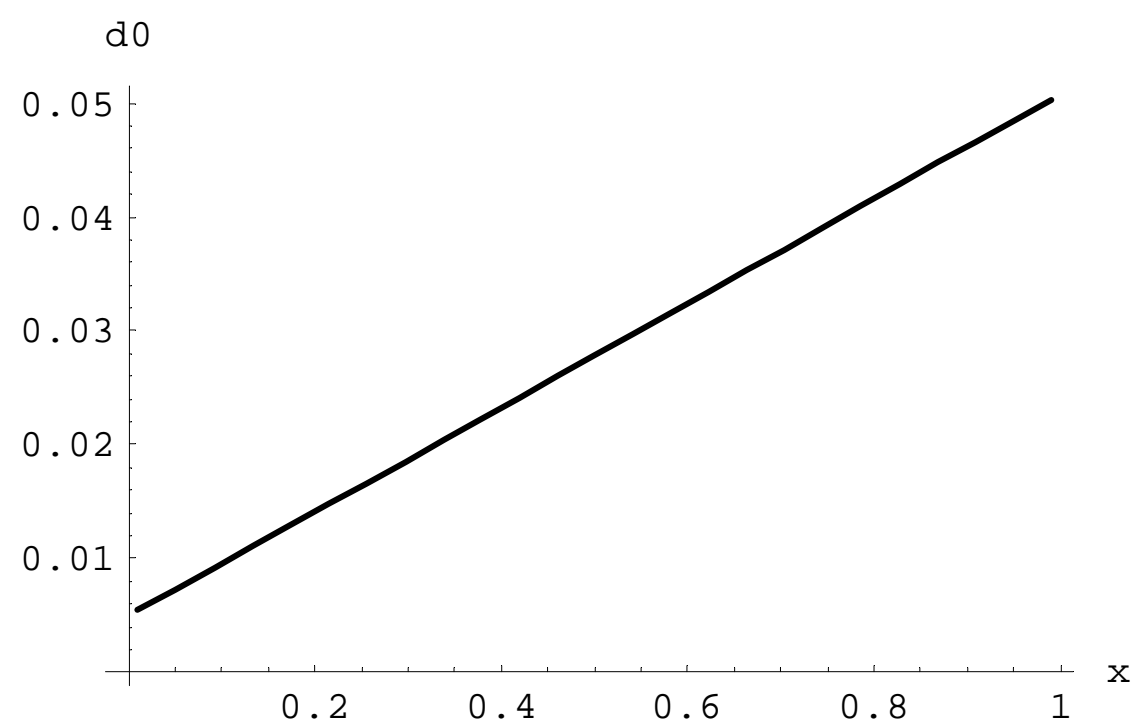

Figure 2b: Impact of distance to jobs on $d_{0}-$ dyads. 


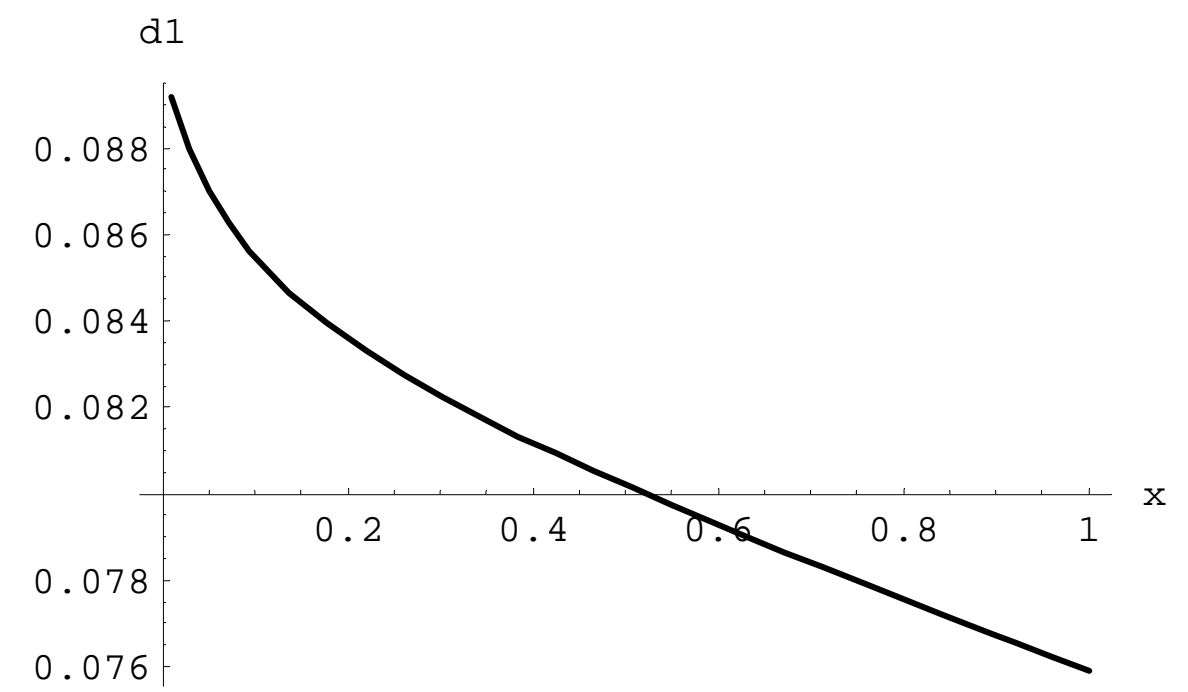

Figure 2c: Impact of distance to jobs on $d_{1}-$ dyads.

Concerning the effect of location $x$ on dyads $d_{2}$, the relationship is non-monotonic (Figure $2 \mathrm{~d})$. Indeed, individuals close to and far away from jobs spend more time in $d_{2}$-dyads than those who live in intermediary locations because the former have a lot of contacts with weak ties and thus obtain quickly a job while the latter have few contacts with weak ties and thus spend most of time with strong ties, which help them to get a job only if their best friend is employed.

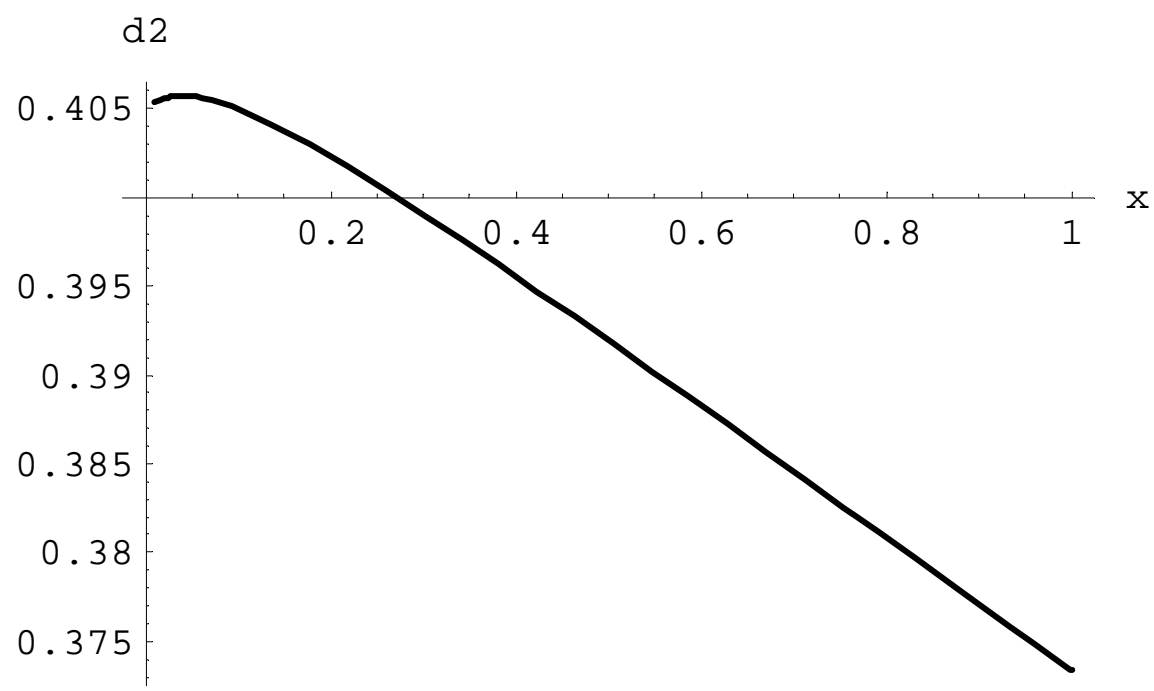

Figure 2d: Impact of distance to jobs on $d_{2}-$ dyads. 
To summarize, when meeting weak ties involves commuting to a business center, individuals who are close to jobs obtain a lot of information about jobs, spend little time in a $d_{0}$-dyad (both friends are unemployed) and experience low unemployment rate. On the contrary, those who live far away from jobs spend most of their time with strong ties and thus get little information from weak ties. This means that when they belong to a $d_{0}-$ dyad, where their best friend is also unemployed, they have little chance to find a job and are stuck in an unemployment state. This is why they experience higher unemployment rates.

\subsection{Choosing social interactions}

We would like now to extend the model so that $\omega$ is chosen by individuals. The timing is as in the previous section. We assume that there is some cost of interacting with weak ties. Let $c$ denotes the marginal cost of these interactions. The expected utility is still given by (17) but we need to add the interaction costs. We have:

$$
E V(\omega, x)=e^{*}(\omega)(y-\tau x)+\left[1-e^{*}(\omega)\right](b-s \tau x)-R(x)-c \omega
$$

where $e^{*}(\omega)$ is defined by (11). Each individual optimally chooses $\omega$ that maximizes $E V(\omega, x)$. The first-order condition yields:

$$
\frac{\partial E V(\omega, x)}{\partial \omega}=\frac{\partial e^{*}(\omega)}{\partial \omega}[y-b-(1-s) \tau x]-c=0
$$

We assume that the second order condition always holds, i.e.

$$
\frac{\partial^{2} e^{*}(\omega)}{\partial \omega^{2}}<0
$$

Observe that $y-b-(1-s) \tau x>0, \forall x \in[0,1]$, and we have seen (see Proposition 4) that if $(22)$ holds, then $\frac{\partial e^{*}(\omega)}{\partial \omega}>0$. We have the following result:

Proposition 8 Assume (22) and consider steady-state equilibrium $\mathcal{I}$. Then there exists a unique interior $\omega^{*}$ that maximizes $E V(\omega, x)$ and

(i) workers living further away from jobs will interact less with weak ties than those residing closer to jobs, i.e.

$$
\frac{\partial \omega^{*}}{\partial x}<0
$$


(ii) higher wages or lower unemployment benefits will increase the interactions with weak ties, i.e.

$$
\frac{\partial \omega^{*}}{\partial y}>0 \quad \frac{\partial \omega^{*}}{\partial b}<0
$$

(iii) higher commuting costs will decrease the interactions with weak ties, i.e.

$$
\frac{\partial \omega^{*}}{\partial \tau}<0
$$

Workers want to interact with weak ties because it increases their probability to be employed (or, equivalently, the time they spend employed during their lifetime), i.e. $\frac{\partial e^{*}(\omega)}{\partial \omega}>$ 0 . However, because it is always more expensive to commute to the business district when employed than when unemployed (i.e. $\tau>s \tau$ ), the marginal gain of interacting with weak ties is higher for workers residing closer to jobs than for those locating further away. As a result, workers residing closer to jobs will interact more with weak ties than those residing further away from jobs. Concerning wage $y$ and unemployment benefit $b$, a higher $y$ or $b$ increases the value of employment and, since $e^{*}(\omega)$ and $\omega$ are positively related, workers will interact more with weak ties. The same intuition applies for commuting $\operatorname{costs} \tau$.

The model can be closed as in the previous section. What is interesting is that all endogenous variables are now a function of $x, y, b, \tau$. In particular,

$$
\begin{aligned}
& \frac{\partial u^{*}}{\partial x}=\frac{\partial u^{*}}{\partial \omega} \frac{\partial \omega}{\partial x}>0 \\
& \frac{\partial u^{*}}{\partial b}=\frac{\partial u^{*}}{\partial \omega} \frac{\partial \omega}{\partial b}>0 \\
& \frac{\partial u^{*}}{\partial \tau}=\frac{\partial u^{*}}{\partial \omega} \frac{\partial \omega}{\partial \tau}>0
\end{aligned}
$$

As before, workers residing further away will experience higher unemployment. Also, higher unemployment benefits or commuting costs leads to higher unemployment. These results are conformed to the intuition, even though the mechanisms are new.

\section{Discussion}

Because of the results of the previous section, our model can provide a mechanism explaining why black workers, who tend to live far away from jobs in the United States, experience high unemployment rates. This is known as the "spatial mismatch hypothesis". Indeed, first formulated by Kain (1968), the spatial mismatch hypothesis states that, residing in urban 
segregated areas distant from and poorly connected to major centres of employment growth, black workers face strong geographic barriers to finding and keeping well-paid jobs. In the US context, where jobs have been decentralized and blacks have stayed in the central parts of cities, the main conclusion of the spatial mismatch hypothesis is that distance to jobs is the main cause of high unemployment rates. Since Kain's study, hundreds of others have been conducted trying to test the spatial mismatch hypothesis (see, in particular, the literature surveys by Ihlanfeldt and Sjoquist, 1998; Ihlanfeldt, 2006; Zenou, 2008). The usual approach is to relate a measure of labor-market outcomes, typically employment or earnings, to another measure of job access, typically some index that captures the distance between residences and centres of employment. The general conclusions are: (a) poor job access indeed worsens labor-market outcomes, (b) black and Hispanic workers have worse access to jobs than white workers, and (c) racial differences in job access can explain between one-third and one-half of racial differences in employment.

Despite this huge empirical literature, few theoretical models have been proposed (for a survey on the theoretical literature, see Gobillon et al., 2007; Zenou, 2006b). The standard approach is to use a search model to show that distant workers tend to search less (due to lack of information about jobs or less opportunities to find a job) and thus stay longer unemployed (Coulson et al., 2001; Wasmer and Zenou, 2002).

In the present paper, we propose an alternative explanation. Building on Granovetter $(1973,1974,1983)$ 's idea that weak ties are superior to strong ties for providing support in getting a job, we have developed a model in which workers who live far away from jobs tend to have less connections to weak ties. As underscored by Granovetter, in a close network where everyone knows each other, information is shared and so potential sources of information are quickly shaken down so that the network quickly becomes redundant in terms of access to new information. In contrast Granovetter stresses the strength of weak ties involving a secondary ring of acquaintances who have contacts with networks outside ego's network and therefore offer new sources of information on job opportunities.

Our explanation of the spatial mismatch is that distant (black) workers live in neighborhoods based on closed networks, which are limited in getting information about possible jobs. Because of the lack of good public transportation in the US, it is costly (both in terms of time and money) to commute to business centers to meet other types of people who can provide other source of information about jobs. If distant (black) workers mainly rely on their strong ties and if the latter are unemployed, there is then little chance to escape unemployment and to find a job. ${ }^{15}$ Our result is consistent with the findings of Conley and

\footnotetext{
${ }^{15}$ Even if this is beyond the scope of this paper, our model could explain the emergence of a "black culture"
} 
Topa (2002). They study unemployment clustering in Chicago between 1980 and 1990 with respect to different social and economic distance metrics that reflect the structure of agents' social networks. They show that racial and ethnic composition variables are the single most important factor in explaining the observed correlation patterns.

Our result is also related to that of Calvó-Armengol and Jackson (2004). Contrary to the present model where only a very specific network structure (i.e. the dyad) is assumed, they explicitly model a social network (which can have any possible structure) where information flows between individuals having a link with each other. They show that there clustering of workers with the same status is likely to emerge in equilibrium since, in the long run (i.e. steady state), employed workers tend to be friends with employed workers. Apart from the fact that there is no urban space, the main difference with our approach is that individuals exchange job information only with their strong ties (as defined by their direct friends). In their model, weak ties (as defined by friends of friends) will indirectly help individuals because, by providing job information to their strong ties, they help them to become employed. The two approaches are complementary. In Calvó-Armengol and Jackson (2004), if because of some initial condition some black workers are unemployed, then in steady-state they will still be unemployed because both their strong and weak ties will also be unemployed. In our framework, it is segregation and distance to a business center that make black workers only interacting with strong ties, who are themselves likely to be unemployed. ${ }^{16}$

To conclude, we believe that weak ties generate 'bridging' social capital. Bridging social capital refers to ties across networks that may make the resources exist in one network accessible to a member of another. These social relationships enable members to 'get ahead'. These are needed to extend beyond family to connect to a broader range of resources and opportunities that exist in networks to which they are otherwise not connected. If black workers do not have access to weak ties (especially whites), in particular because they are segregated and separated from business centers, then their main source of information about jobs will be provided by their strong ties. But if the latter are themselves unemployed, the chance to escape unemployment will be very low.

in areas far away from jobs since distance to jobs induces the black population to rely mostly on strong ties.

${ }^{16}$ Observe that we have not explicitly modelled black and white workers. However, if, for example, we impose housing discrimination so that blacks are obliged to live in the suburbs, then the main results of our model will be true. 


\section{References}

[1] Akerlof, G. (1997), "Social distance and social decisions," Econometrica 65, 1005-1027.

[2] Ballester, C., Calvó-Armengol, A. and Y. Zenou (2006), "Who's who in networks. Wanted: the key player," Econometrica 74, 1403-1417.

[3] Bayer, P., Ross, S.L. and G. Topa (2005), "Place of work and place of residence: Informal hiring networks and labor market outcomes," NBER Working Paper No. 11507.

[4] Brueckner, J.K. and A.G. Lagey (2008), "Social interaction and urban sprawl," Journal of Urban Economics, forthcoming.

[5] Bisin, A. and T. Verdier (2000), "Beyond the melting pot: Cultural transmission, marriage, and the evolution of ethnic and religious traits," Quarterly Journal of Economics $115,955-988$.

[6] Calvó-Armengol, A. and M. Jackson (2004), "The effects of social networks on employment and inequality," American Economic Review 94, 426-454.

[7] Calvó-Armengol, A., Verdier, T. and Y. Zenou (2007), "Strong and weak ties in employment and crime," Journal of Public Economics 91, 203-233.

[8] Conley, T.G. and G. Topa (2002), "Socio-economic distance and spatial patterns in unemployment," Journal of Applied Econometrics 17, 303-327.

[9] Coulson, E., Laing, D. and P. Wang (2001), "Spatial mismatch in search equilibrium," Journal of Labor Economics 19, 949-972.

[10] Fu, S. (2005), "What has been capitalized into property values: Human capital, social capital, or cultural capital?" U.S. Census Bureau Center for Economic Studies, Working Paper No. 05-25.

[11] Fujita, M. (1989), Urban Economic Theory, Cambridge: Cambridge University Press.

[12] Fujita, M. and J.-F. Thisse (2002), Economics of Agglomeration. Cities, Industrial Location, and Regional Growth, Cambridge: Cambridge University Press.

[13] Glaeser, E.L. (2000), "The future of urban economics: Non-market interactions," Brookings-Wharton Papers on Urban Affairs 1, 101-150. 
[14] Glaeser, E.L. Sacerdote, B., and J. Scheinkman (1996), "Crime and social interactions," Quarterly Journal of Economics 111, 508-548.

[15] Gobillon, L., Selod, H. and Y. Zenou (2007), "The mechanisms of spatial mismatch," Urban Studies 44, 2401-2427.

[16] Goyal, S. (2007), Connections: An Introduction to the Economics of Networks, Princeton: Princeton University Press.

[17] Granovetter, M.S. (1973), "The strength of weak ties," American Journal of Sociology $78,1360-1380$.

[18] Granovetter, M.S. (1974), Getting a Job: A Study of Contacts and Careers, Cambridge, MA: Harvard University Press.

[19] Granovetter, M.S. (1983), "The strength of weak ties: A network theory revisited," Sociological Theory 1, 201-233.

[20] Helsey, R.W. and W.C. Strange (2007), "Urban interactions and spatial structure," Journal of Economic Geography 7, 119-138.

[21] Henning C. and M. Lieberg (1996), "Strong ties or weak ties? Neighbourhood networks in a new perspective," Scandinavian Housing and Planning Research 13, 3-26.

[22] Ihlanfeldt, K.R. (2006), "A primer on spatial mismatch within urban labor markets," In: R. Arnott and D. McMillen (Eds.), A Companion to Urban Economics, Boston: Blackwell Publishing, pp. 404-417.

[23] Ihlanfeldt, K. R. and D. Sjoquist (1998), "The spatial mismatch hypothesis: A review of recent studies and their implications for welfare reform," Housing Policy Debate 9, 849-892.

[24] Jackson, M.O. (2008), Social and Economic Networks, Princeton: Princeton University Press, forthcoming.

[25] Kain, J. (1968), "Housing segregation, negro employment, and metropolitan decentralization," Quarterly Journal of Economics 82, 175-197.

[26] Kan, K. (2007), "Residential mobility and social capital," Journal of Urban Economics 61, 436-457. 
[27] Montgomery, J.D. (1994), "Weak ties, employment, and inequality: An equilibrium analysis," American Journal of Sociology 99, 1212-1236.

[28] Selod, H. and Y. Zenou (2006), "City-structure, job search, and labour discrimination. Theory and policy implications," Economic Journal 116, 1057-1087.

[29] Sigelman, L., Bledsoe, T., Welch, S., and M.W. Combs (1996), "Making contact? Blackwhite social interaction in an urban setting," American Journal of Sociology 101, 13061332 .

[30] Shapiro, C., Stiglitz, J.E. (1984), "Equilibrium unemployment as a worker discipline device," American Economic Review 74, 433-444.

[31] Topa, G. (2001), "Social interactions, local spillovers and unemployment," Review of Economic Studies 68, 261-295.

[32] Vega-Redondo, F. (2007), Complex Social Networks, Econometric Society Monograph Series, Cambridge: Cambridge University Press.

[33] Wasmer, E. and Y. Zenou (2002), "Does city structure affect job search and welfare?," Journal of Urban Economics 51, 515-541.

[34] Zenou, Y. (2006a), "Efficiency wages and unemployment in cities: The case of high relocation costs," Regional Science and Urban Economics 36, 49-71.

[35] Zenou, Y. (2006b), "Urban labor economic theory,", In: R. Arnott and D. McMillen (Eds.), A Companion to Urban Economics, Boston: Blackwell Publishing, pp. 418-439.

[36] Zenou, Y. (2008), "The spatial mismatch hypothesis," In: L. Blume and S. Durlauf (Eds.), The New Palgrave, A Dictionary of Economics, Second Edition, London: MacMillan Press, forthcoming. 


\section{Appendix}

Proof of Proposition 1: We establish the proof in two steps. First, Lemma 1 characterizes all steady-state dyad flows. Lemma 2 then provides conditions for their existence.

Lemma 1 There exists at most two different steady-state equilibria: (i) a full-unemployment equilibrium $\mathcal{U}$ such that $e^{*}=0$ and $u^{*}=1,($ ii $)$ an interior equilibrium $\mathcal{I}$ such that $0<e^{*}<1$ and $0<u^{*}<1$.

Proof. By combining (5) to (8), we easily obtain:

$$
e^{*}=\left[\left(1-\omega+\omega e^{*}\right) \lambda+\delta\right] \frac{2 \omega e^{*} \lambda}{\delta^{2}} d_{0}^{*}
$$

We consider two different cases.

(i) If $e^{*}=0$, then equation (35) is satisfied. Furthermore, using (5) and (6), this implies that $d_{1}^{*}=d_{2}^{*}=0$ and, using (7) and (9), we have $d_{0}^{*}=1 / 2$ and $u^{*}=1$. This is referred to as steady-state $\mathcal{U}$ (full unemployment).

(ii) If $e^{*}>0$, then solving equation (35) yields:

$$
e^{*}=\frac{1}{\lambda \omega}\left[\frac{\delta^{2}}{2 \omega \lambda d_{0}^{*}}-\delta\right]-\frac{(1-\omega)}{\omega}
$$

Define $Z=(1-\omega) / \omega, B=\delta /(\lambda \omega)$. This equation can now be written as:

$$
e^{*}=\frac{B^{2}}{2 d_{0}^{*}}-B-Z
$$

Moreover, by combining (5) and (6), we obtain:

$$
d_{1}^{*}=\frac{2 e^{*}}{B} d_{0}^{*}, \quad d_{2}^{*}=\frac{\left(Z+e^{*}\right) e^{*}}{B^{2}} d_{0}^{*}
$$

- Let us first focus on the case where $e^{*}=1$. In that case, it has to be that only $d_{2}$-dyads exist and thus $d_{0}^{*}=d_{1}^{*}=0$, which, using (37) implies that: $d_{2}^{*}=0$. So this case is not possible.

- Let us now thus focus on the case: $0<e^{*}<1$ (which implies that $0<u^{*}<1$ )

By plugging (36) and (37) in (7) and after some algebra, we obtain that $d_{0}^{*}$ solves $\Phi\left(d_{0}^{*}\right)=$ 0 where $\Phi(x)$ is the following second-order polynomial:

$$
\Phi\left(d_{0}^{*}\right)=-\frac{Z}{B} x^{2}-\frac{(1+Z)}{2} x+\left(\frac{B}{2}\right)^{2}
$$




\section{Lemma 2}

(i) The steady-state equilibrium $\mathcal{U}$ always exists.

(iv) The steady-state equilibrium $\mathcal{I}$ exists when $\delta<\lambda[\omega+\sqrt{\omega(4-3 \omega)}] / 2$.

\section{Proof.}

(i) In this equilibrium $e^{*}=0$, which implies that $h(e)=(1-\omega) \lambda$ and $q(e)=0$. There are only $d_{0}$-dyads so all workers are unemployed and will never receive a job offer since $q(e)=0$. So when a $d_{0}$-dyad is formed it is never destroyed and thus this equilibrium is always sustainable.

(ii) We know from Lemma 1 that a steady-state $\mathcal{I}$ exists and that $e^{*} \neq 1$. We now have to check that $e^{*}>0$ and $0<d_{0}^{*}<1 / 2$. Let us thus verify whether there exists some $0<d_{0}^{*}<1 / 2$ such that $\Phi\left(d_{0}^{*}\right)=0$, where $\Phi(\cdot)$ is given by (38). We have $\Phi(0)=(B / 2)^{2}>0$ and $\Phi^{\prime}(0)=-(1+Z) / 2<0$. Therefore, (38) has a unique positive root smaller than $1 / 2$ if and only if

$$
\Phi(1 / 2)=\frac{1}{4}\left[B^{2}-(1+Z)-\frac{Z}{B}\right]=\frac{1}{4}\left(1+\frac{1}{B}\right)\left(B^{2}-B-Z\right)<0 .
$$

The unique positive solution to $x^{2}-x-Z=0$ is $[1+\sqrt{(4-3 \omega) / \omega}] / 2$. Then, $d_{0}^{*}<1 / 2$ if and only if $B<[1+\sqrt{(4-3 \omega) / \omega}] / 2$, equivalent to:

$$
\delta<\frac{\lambda}{2}[\omega+\sqrt{\omega(4-3 \omega)}]
$$

Observe that $d_{0}^{*}<1 / 2$ guarantees that $e^{*}>0$.

\section{Proof of Proposition 4:}

(i) By totally differentiating (12), we obtain:

$$
\frac{\partial d_{0}^{*}}{\partial \omega}=\frac{\frac{\lambda}{\delta} d_{0}^{2}+\frac{1}{2 \omega^{2}} d_{0}-\frac{\delta^{2}}{2 \lambda^{2} \omega^{3}}}{2 \frac{\lambda(1-\omega)}{\delta} d_{0}+\frac{1}{2 \omega}}
$$

and thus

$$
\operatorname{sgn} \frac{\partial d_{0}^{*}}{\partial \omega}=\operatorname{sgn}\left[\frac{\lambda}{\delta} d_{0}^{2}+\frac{1}{2 \omega^{2}} d_{0}-\frac{\delta^{2}}{2 \lambda^{2} \omega^{3}}\right]
$$

Let us study

$$
\Phi\left(d_{0}\right) \equiv \frac{\lambda}{\delta} d_{0}^{2}+\frac{1}{2 \omega^{2}} d_{0}-\frac{\delta^{2}}{2 \lambda^{2} \omega^{3}}
$$




$$
\begin{gathered}
\Phi(0)=-\frac{\delta^{2}}{2 \lambda^{2} \omega^{3}}<0 \\
\Phi^{\prime}\left(d_{0}\right)=2 \frac{\lambda}{\delta} d_{0}+\frac{1}{2 \omega^{2}}>0 \text { when } d_{0} \geq 0 \\
\Phi^{\prime \prime}\left(d_{0}\right)=2 \frac{\lambda}{\delta}>0
\end{gathered}
$$

We have a quadratic function that crosses only once the positive orthant. Let us calculate $\widehat{d_{0}}$ the value for which $\Phi\left(d_{0}\right)$ crosses the $d_{0}$-axis. For that, we have to solve: $\Phi\left(\widehat{d_{0}}\right)=0$. It is easy to verify that:

$$
\widehat{d_{0}}=\frac{\delta}{4 \lambda \omega^{2}}\left(\sqrt{1+\frac{8 \delta \omega}{\lambda}}-1\right)>0
$$

It should be clear that if $\widehat{d}_{0}<1 / 2$, then $\Phi\left(d_{0}\right)<0$ for $0<d_{0}<1 / 2$ and thus $\frac{\partial d_{0}^{*}}{\partial \omega}<0$. Let us thus check that $\widehat{d}_{0}<1 / 2$, which is equivalent to:

$$
\Omega\left(\frac{\delta}{\lambda}\right) \equiv 2\left(\frac{\delta}{\lambda}\right)^{3}-\omega \frac{\delta}{\lambda}-\omega^{3}<0
$$

We have:

$$
\begin{gathered}
\Omega(0)=-\omega^{3} \\
\Omega^{\prime}\left(\frac{\delta}{\lambda}\right)=6\left(\frac{\delta}{\lambda}\right)^{2}-\omega
\end{gathered}
$$

with

$$
\Omega^{\prime}\left(\frac{\delta}{\lambda}\right)<0 \Longleftrightarrow \frac{\delta}{\lambda}<\sqrt{\frac{\omega}{6}}
$$

It is easy to verify that

$$
\sqrt{\frac{\omega}{6}}<\frac{[\omega+\sqrt{\omega(4-3 \omega)}]}{2}
$$

so that when $\frac{\delta}{\lambda}<\sqrt{\frac{\omega}{6}}$ (i.e. condition (22)) holds, then (10) also holds.

To summarize, when $(22)$ holds, then $\widehat{d}_{0}<1 / 2$ and thus $\frac{\partial d_{0}^{*}}{\partial \omega}<0$.

(ii) By totally differentiating (11), we obtain: 


$$
\begin{aligned}
\frac{\partial e^{*}}{\partial \omega} & =\frac{\partial B}{\partial \omega}\left(\frac{B}{2}-1\right)-\frac{B^{2}}{4} \frac{1}{d_{0}} \frac{\partial d_{0}^{*}}{\partial \omega}-\frac{\partial Z}{\partial \omega} \\
& =\frac{-\delta}{\lambda \omega^{2}}\left(\frac{\delta}{2 \lambda \omega}-1\right)-\frac{\delta^{2}}{4 \lambda^{2} \omega^{2}} \frac{1}{d_{0}} \frac{\partial d_{0}^{*}}{\partial \omega}+\frac{1}{\omega^{2}} \\
& =\frac{\delta}{\lambda \omega^{2}}-\frac{\delta^{2}}{4 \lambda^{2} \omega^{2}} \frac{1}{d_{0}} \frac{\partial d_{0}^{*}}{\partial \omega}+\frac{1}{\omega^{2}}-\frac{\delta^{2}}{2 \lambda^{2} \omega^{3}} \\
& =\frac{1}{\omega^{2}}\left[\frac{\delta}{\lambda}-\frac{\delta^{2}}{4 \lambda^{2}} \frac{1}{d_{0}} \frac{\partial d_{0}^{*}}{\partial \omega}+1-\frac{\delta^{2}}{2 \lambda^{2} \omega}\right]
\end{aligned}
$$

Thus, we have:

$$
\frac{\partial e^{*}}{\partial \omega}>0 \Longleftrightarrow \frac{\delta}{\lambda}-\frac{\delta^{2}}{4 \lambda^{2}} \frac{1}{d_{0}} \frac{\partial d_{0}^{*}}{\partial \omega}+1>\frac{\delta^{2}}{2 \lambda^{2} \omega}
$$

Since $\frac{\partial d_{0}^{*}}{\partial \omega}<0$ when $(22)$ holds, then it suffices to show that:

$$
\frac{\delta}{\lambda}+1>\frac{\delta^{2}}{2 \lambda^{2} \omega}
$$

which is always true if

$$
\frac{\delta^{2}}{2 \lambda^{2} \omega}<1
$$

This is equivalent to:

$$
\frac{\delta}{\lambda}<\sqrt{2 \omega}
$$

But since

$$
\sqrt{\frac{\omega}{6}}<\sqrt{2 \omega}
$$

is always true, then condition (22) guarantees that both

$$
\frac{\partial d_{0}^{*}}{\partial \omega}<0 \text { and } \frac{\partial e^{*}}{\partial \omega}>0
$$

Since $e^{*}=1-u^{*}, \frac{\partial e^{*}}{\partial \omega}>0 \Leftrightarrow \frac{\partial u^{*}}{\partial \omega}<0$. Finally, from (13) and (14), it is easy to see that $\frac{\partial d_{1}^{*}}{\partial \omega}$ and $\frac{\partial d_{2}^{*}}{\partial \omega}$ cannot be signed. 